\title{
The Open Sky Underground
}

Igor Beauvois and Olivier Las Vergnas

210 av. Pierre-Brossolette, F-92240 Malakoff, France

From 1985 March 26 to April 5, a special public astronomical education campaign was mounted in 16 stations of the Paris Métro. Apart from static displays, items included two planetariums, mirror-making, numerous round-table discussions, astronomical films, etc. Millions of people saw some part of these displays and surveys showed that many returned several times. The event was coordinated by the Association Nationale Science Techniques Jeunesse [National Association for Youth Science and Technology] and involved many official and private bodies, 30 astronomical groups, and 420 employees of the RATP [Régie autonome des transport parisiens - Paris city transport authority].

[Four contributions dealt directly with the question of the teaching of astronomy in schools. This whole subject is the topic of the forthcoming IAU Colloquium 105 "Teaching of Astronomy: Present and Future". - Eds.]

\section{Teaching Astronomy in Schools}

Cecylia Iwaniszewska

Institute of Astronomy, N. Copernicus University, PL-87-100 Torun, Poland

This contribution summarized the ways in which astronomical teaching was evolving and some of the teaching aids that could be employed. The work of GIREP (Groupe International de Recherche sur l'Enseignment de la Physique) - which holds conferences on the teaching of physics, including astronomy, every two years - was described together with some material reported at the 1986 conference which was devoted to astronomy.

\section{Teaching Astronomy and the Vital Role of the True Amateur}

\section{H. Robert Mills}

83 Firs Road, Firsdown, Salisbury, Wilts. SP5 1SW, U.K.

This contribution summarized the situation in the United Kingdom where there are 5 organisations that are concerned with astronomical observation, but where there are hopes that a single unifying committee may be formed. Practical work for pupils was essential and many examples of simple equipment and practical applications were shown. 